\title{
ASCENDING NOREPINEPHRINE PATHWAYS IMPAIRED IN EXPERIMENTAL HYDROCEPHALUS
}

\author{
Kazumasa EHARA, Satoshi MATSUMOTO, Nobuyoshi YOSHIDA*, \\ Takayoshi KUNO* and Chikako TANAKA*,** \\ Department of Neurological Surgery, *Departmont of Pharmacology. \\ Kobo University School of Medicine. Kobe 650. Japan
}

Accepted October 26, 1981

Morphological and histopathological changes in the hydrocephalus have been extensively investigated in humans and in experimental animals, but little is known of the related metabolic changes. The levels of monoamine metabolites in cerebro-spinal fluid are reportedly closely related to the prognosis, the location of obstruction, and the pathophysiology of hydrocephalus $(1,2)$. Owman et al. reported that intracranial hypertension induced by injection of kaolin produced a transient decrease in norepinephrine (NE) levels in rabbit brain (3). As alterations in the noradrenergic nerve system in the hydrocephalic brain have not been documented, we attempted to assess the changes in the central noradrenergic nerve system in hydrocephalic rats using the combination of a sensitive microassay method for measuring NE using a high performance liquid chromatography (HPLC) with a histofluorescence method for demonstrating monoamines.

Six week old male Wistar rats were anesthetized with sodium pentobarbital (40 $\mathrm{mg} / \mathrm{kg}$, i.p.) and given $0.1 \mathrm{ml}$ of a suspension of kaolin (250 mg hydrated aluminium silicate in $1 \mathrm{ml}$ of $0.9 \%$ saline) which was injected into the cisterna magna, after the atlanto-occipital membrane had been exposed through a midline incision (4-6). In the control rats, the same amount of normal saline was

* To whom reprint requests stould be addressed. injected using the same procedure. All these rats were killed 4 weeks later.

For chemical assay, the rats were decapitated and brains were rapidly removed and dissected on ice into 7 regions according to the method of Glowinski and Iversen (7): frontal cortex, occipital cortex, hippocampus, striatum, hypothalamus, cerebellum and medulla plus pons. The samples were homogenized in $5 \mathrm{ml}$ of ice cold $0.4 \mathrm{~N}$ perchloric acid containing $5 \mathrm{mg}$ sodium meta-bisulfite and $20 \mathrm{mg}$ ethylenediamine tetraacetate, and centrifuged for $10 \mathrm{~min}$ at 10.000 r.p.m. Supernatants were assayed for $N E$ by the method of Keller et al. using a HPLC system with an electrochemical detector (Yanaco) (8).

For histochemical demonstration of NE, we used a method combining formaldehyde gas treatment $(9,10)$ and glyoxylic acid perfusion $(10,11)$. The rats were anesthetized with sodium pentobarbital (40 $\mathrm{mg} / \mathrm{kg}$, i.p.), and the hearts were exposed without artificial ventilation. These rats were then perfused with $600 \mathrm{ml} / \mathrm{kg}$ of ice cold $2 \%$ glyoxylic acid in phosphate buffered Ringer's solution through the left ventricle. Immediately after the perfusion, the brain was removed and rapidly frozen in prechilled isopentane with liquid nitrogen. The specimens were freezedried at $-35^{\circ} \mathrm{C}$ for 7 days and then exposed to vapor generated from standardized paraformaldehyde at $80^{\circ} \mathrm{C}$ for $1 \mathrm{hr}$. After this treatment, the specimens were embedded 
in paraffin in vacuo. Transverse serial sections of $100 \mathrm{~km}$ thickness were prepared. Each $10 \mathrm{\mu m}$ thick slice was mounted with a mixture of Entellan and xylene. A Zeiss fluorescence microscope was used for analysis.

In all the rats given kaolin, there was some degree of ventricular dilatation, but the degree of hydrocephalus varied from slight to extensive, even after injection of the same amounts of kaolin. The rats given kaolin ate less food, the body weight decreased, there was a drowsiness and a paretic ambulation after 1 week, an enlarged head after 2 weeks, and a domed head by 4 weeks.

The brain NE levels were decreased in the frontal cortex, the hippocampus, the hypothalamus and the cerebellum in the hydrocephalus induced rats 4 weeks after the injection of kaolin. In particular, the level of NE in the frontal cortex was decreased to $67 \%$ of the control value. The NE levels in the striatum and medulla plus pons remained unaltered (Table 1).

In the hydrocephalic brains prepared for histochemical study, the catecholamine fluorescence was decreased in the nerve terminals of the frontal cortex, the hippocampal cortex. the cerebellar cortex and the periventricular layer of the hypothalamus if the lateral and third ventricles were dilated (photos not included). Even in the mild case, catecholamine fluorescence in the frontal cortex was decreased. Fluorescent cell bodies in the locus coeruleus were swollen, and catecholamine fluorescent materials had accumulated in neurons as shown in Fig. 1. Axons of the subcoeruleus neurons were swollen. Histofluorescence remained unaltered in the lower brain stem, the supraoptic nucleus, and the lateral hypothalamus.

The distribution of noradrenergic fibers arising from the locus coeruleus has been studied by examining changes in histofluorescence (12) and NE contents following lesions of the locus coeruleus or the related axon pathways (13). These studies indicated that the major noradrenergic innervation to the cerebral cortex, cerebellum and hippocampus is from the ipsilateral locus coeruleus, and that the region of the hypothalamus is supplied mainly by axons from noradrenergic neurons which emanate from the locus coeruleus and from the subcoeruleus area (14).

Reduction of NE in the frontal cortex, cerebellum and hippocampus and changes in histofluorescence in these brain areas and the

Table 1. Changes in norepinephrine levels in hydrocephalic rat brains

\begin{tabular}{|c|c|c|c|c|}
\hline & \multicolumn{2}{|c|}{ Control } & \multicolumn{2}{|c|}{ Hydrocephalus } \\
\hline & $\begin{array}{l}\text { Wet Weight } \\
\text { (mg) }\end{array}$ & $\begin{array}{c}\text { Norepinephrine } \\
(\mathrm{ng} / \mathrm{gr})\end{array}$ & $\begin{array}{l}\text { Wet Weight } \\
\qquad(\mathrm{mg})\end{array}$ & $\begin{array}{c}\text { Norepinephrine } \\
\text { (ng/gr) }\end{array}$ \\
\hline Frontal cortex & $442 \pm 10$ & $253 \pm 18$ & $431 \pm 8$ & $170 \pm 9^{* *}$ \\
\hline Occipital cortex & $186 \pm 8$ & $135 \pm 8$ & $174 \pm 8$ & $122 \pm$ \\
\hline Hippocampus & $100 \pm 7$ & $217 \pm \quad 9$ & $97 \pm 6$ & $172 \pm$ \\
\hline Striatum & $98 \pm 5$ & $236 \pm 44$ & $110 \pm 8$ & $316=41$ \\
\hline Hypothalamus & $72 \pm 7$ & $1977 \pm 141$ & $66 \pm 6$ & $1557 \pm 216$ \\
\hline Medulla+pons & $248=8$ & $481=27$ & $249 \pm 6$ & $507 \pm 23$ \\
\hline Cerebellum & $265 \pm 8$ & $120 \pm 4$ & $276 \pm 9$ & $87 \pm 8^{*}$ \\
\hline
\end{tabular}

The hydrocephalus was induced by injection of a kaolin suspension into the ciserna magna. Brains were dissected into 7 regions. Norepinephrine was assayed using HPLC. Each value is the mean \pm S.E. of 8 determinations. Significantly different from each control. ${ }^{*}: P<0.01,{ }^{* *}: P<0.001$. (See text for details) 


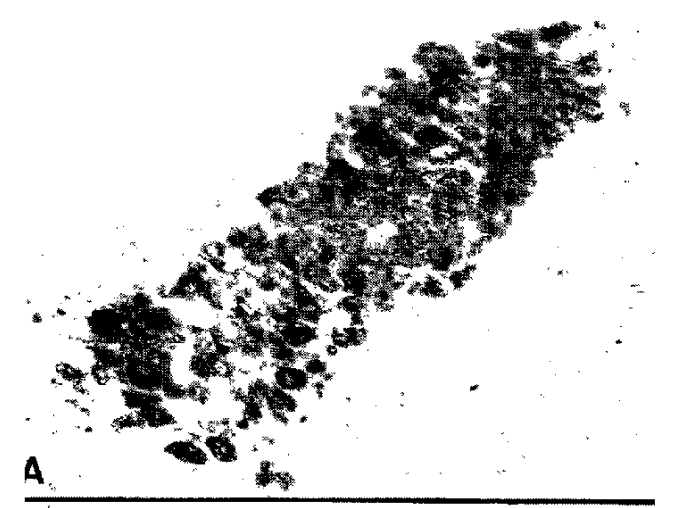

3

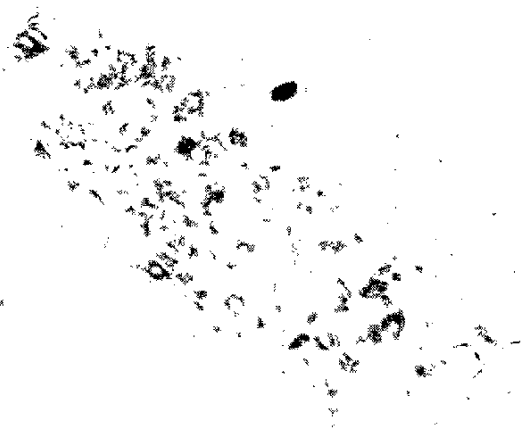

Fig. 1. Norepinophrine fluoresconce by a method combining formaldenyde gas treatrient with glyoxylic acid perfusion (X64). A: i.ocus coeruleus in hydrocephalic rats. $B$ : iocus cocruteus in control rats. Note the swelling of the cell bodies and the stronger fluorescence in the locus coeruleus in hydrocephalic rats (A).

locus coeruleus strongly suggest damage to the coerulocortical and coerulocerebellar noradrenergic pathways. Changes of histofluorescence in the periventricular hypothalamus, the locus coeruleus and the subcoeruleus indicate damage to the periventricular NE system.

The histofluorescence findings of NE accumulation in the nerve cell bodies of the locus coeruleus suggested damage to the nerve fibers or terminals rather than to the nerve cell bodies, as supported by our findings that uneven reduction of NE levels was apparent in various cortical regions. If the neurons of the locus coeruleus were highly degenerated, a reduction would be produced to almost the same extent in all cortical regions (13). This idea is supported by the histopathological findings on experimentally-induced hydrocephalus that the edema of the white matter is the earliest pathological lesion but not the gray matter $(5,15)$ and that the major atrophic process in hydrocephalus probably involves the neuroglia and axorial collaterals rather than the neurons, nerve terminals and the main axonal trunks until the end stage (16).

Acinowledgments: This study was supported in part by Grants for research from the Ministry of Health and Welfare and the Ministry of Education. Science and Culture. Japan. We thank M. Ohara for comments on the manuscript.

\section{REFERENCES}

1) Moir, A.T.B., Aschcroft, G.W., Crawford, T.B.B., Eccleston, D. and Guldberg, H.C.: Cerebral metabolites in cerebrospinal fluid as a biochemical approach to the brain. Brain 93, 357-368 (1970)

2) Inagawa, T., Ishikawa, S. and Uozumi, T.: Homovanillic acid and 5-hydroxyindoleacetic acid in the ventricular CSF of comatose pationts with obstructive hydrocephalus. J. Neurosurg. 52, 635-641 (1980)

3) Owman, CH., Rosengren, E. and West, K.A.: influence of various intracranial pressure levels on the concentration of certain arylethylamines in rabbit brain. Experientia 27, 1036-1037 (1971)

4) Lindauer, M.A. and Griffith, J.Q., Jr.: Cerebrospinal fluid pressure, hydrocephalus and blood pressure in the cat following intracisternal injection of colloidal kaolin. Proc. Soc. exp. Biol. Med. 39, 547-549 (1938)

5) Matsumoto, S.. Hirayama, A., Yamasaki, S., Shirataki, K. and Fujiwara, K.: Comparative study of various models of experimental hydrocephalus. Child's Brain 1, 236-242 (1975)

6) Torvik, A. and Stenwig, A.E.: The pathology of experimental obstructive hydrocephalus, electron microscopic observations. Acta Neurooathol. 38, 21-26 (1977)

7) Glowinski, J. and Iversen, L.L.: Regional studies of catecholamines in the rat brain-I. J. Neurochem. 13,655-669 (1966)

8) Keller, R., Oke, A., Mefford, I. and Adams, R.N.: Liquid chromatographic analysis of catechol- 
amines, routine assay for regional brain mapping. Lifo Sci. 19, 995-1004 (1976)

9) Falck, B., Hillarp, N.A., Thieme, G. and Torp. A.: Fluorescence of catecholamines and related compounds condensed with formaldehyde. J. Histochem. Cytochem. 10, 348-354 (1962)

10) Yoshida, N., Taniyama, $K$. and Tanaka, $C$.: Adrenergic innervation and cyclic adenosine 3'5'-monophosphate levels in responso to norepinephrine in stomach of postnatal rats. J. Pharmacol. exp. Ther. 211, 174-180 (1979)

11) Björklund, A., Lindvall, O. and Svensson, L.A.: Mechanisms on fluorophore formation in the histochemical glyoxylic acid method for monoamines. Histochemie 32, 113-131 (1972)

12) Ungerstedt, $U$ : Stereotaxic mapping of the monoamine pathways in the rat brain. Acta physiol. scand. 367, Supp. 1-48 (1971)

13) Kobayashi, R.M., Palkovits, M., Kopin, I.J. and Jocobowitz, D.M.: Biochemical mapping of noradrenergic nerves arising from the rat locus coeruleus. Brain Res. 77, 269-279 (1974)

14) Lindvall, $O$. and Bjöklund, A.: The organization of the ascending catecholamine neuron systems in the rat brain. Acta physiol. scand. 412 , Supp. 1-48 (1974)

15) Clark, R.G. and Milhorat, T.H.: Experimental hydrocephalus, Part 3: Light microscopic findings in acute and subacute obstructive hydrocephalus in tho monkev. J. Neurosurg. $32,400-413(1970)$

16) Milhorat, T.H.: Hydrocephalus and the cerebrospinal fluid. p. 115-118. Williams and Wilkins, Baltimore (1972) 